\section{Surge-Voltage Breakdown Characteristics for Electrical Gaps in Oil}

\author{
ROYAL W. SORENSEN \\ FELLOW AIEE
}

\begin{abstract}
Synopsis: This paper, emanating from a request for information regarding surge voltages required to break down gaps in oil, gives surge breakdown voltage values with different gap spacings for $1 / 4$-inch, $1 / 2$-inch, and 1 -inch round rod electrodes with hemispherical ends immersed in transformer oil. As expected, these values are a function of "time to breakdown" but for each condition curves show constant breakdown values for breakdown times of the order of about 16 microseconds and longer with the $11 / 2 \times 40$ negative wave, used on all the tests reported. Particular attention is called to the relatively small amount of oil required for tests of this type, made possible by the special type of test barrel used.
\end{abstract}

I NSULATION co-ordination and oilcircuit-breaker designs make desirable a knowledge of surge voltages required to break down insulating oil. The lack of data pertaining to this subject was called to our attention by E. K. Sadler and J. L. Thompson, engineers with the Kelman Electric and Manufacturing Company. The test results published in this paper were made possible by the co-operation of J. N. Kelman, who provided some of the equipment required for making the tests, and by a great deal of arduous and careful work done by graduate students, particularly G. D. McCann and A. E. Harrison, in the high-voltage laboratory at the California Institute of Technology.

Voltage for making the tests was obtained by means of a 1,500,000-volt Marx circuit surge generator comprising 30

Paper 39-115, recommended by the AIEE committee on instruments and measurements, and mittee on instruments and measurements, and
presented at the AIEE combined summer and $\mathrm{Pa}$ cific Coast convention, San Francisco, Calif., June 26-30, 1939 . Manuscript submitted November 30, 1938; made available for preprinting April 24, 1939.

ROYAL W. SORENSEN is professor of electrical engineering at California Institute of Technology, Pasadena.

1. For all numbered references, see list at end of paper.

periods of subnormal loads, such as Sundays and late night hours, it permits the highest degree of concentration of work. In times of abnormal loads, such as Christmas, New Year's, Easter, or special events of national interest, it expands 50-kv 0.5-microfarad General Electric circuit. The test gaps in oil were formed by using specially constructed electrodes assembled in a test barrel devised by the author and shown in figures 1 and 2 . All tests were made with a standard $11 / 2 \times 40$ negative wave. The voltage for each discharge was measured by means of a cathode-ray oscillograph of the coldcathode continuous-beam type designed and built by Doctor Howard Griest, ${ }^{1}$ and a resistance potentiometer constructed according to the required standards for such work. Figure 3 shows a typical oscillogram. The voltages thus measured were at intervals checked as to peak values by comparison with standard sphere gaps.

All gap test electrodes used were round rods terminating as hemispheres having the same diameter as the rods. This type electrode was chosen in preference to spheres mounted on rods or shanks in order to avoid under surge conditions, uncertainties regarding the influence of shank diameter upon the field uniformity around the gap, and, hence, upon the results obtained by our tests.

Electrodes ranging from one-fourth inch to six inches in diameter were prepared. This report contains data for electrodes having diameters of one-fourth, one-half, one inch, and two inches, respectively. The data for the two-inch electrodes are less complete than for the other rods, because the voltage available, $1,500 \mathrm{kv}$, would not permit tests with the two-inch electrodes at the larger spacings. An increase in surge-generator voltage is being made and further tests will be re-

One reason for the absence of data of the type presented in this paper has been the difficulty encountered in providing a convenient lead-in bushing for making

naturally to accommodate itself to the increased burden. Under all conditions, it handles the telegrams with greater speed and accuracy than ever before, and thus has brought about significant progress in the telegraphic art. capacitors and a suitable d-c charging ported in a later paper. tests of this type. This difficulty we overcame by making a test barrel in which the electrodes were mounted, and its lead-in bushing of insulating material having about the same dielectric constant as insulating oil. Fortunately, we had available for making this device two cylinders made of paper and varnish, known by the trade names Micarta and Herkolite, respectively. The larger cylinder, 40 inches in diameter and 72 inches long, forms the test chamber, and the smaller one, $23^{3} / 4$ inches in diameter and 48 inches long, serves as a lead-in bushing. These cylinders were open at both ends when obtained. An oil-tight bottom for the test barrel was obtained by placing the insulating cylinder upon a steel plate on the surface of which a circular gasket seat had been machined. A cork gasket which could be clamped tightly between the end of the cylinder and the gasket seat was used. A steel clamping band, as shown in figure 2, drawn tightly around the Micarta cylinder by a bolt and drawn down hard upon the cork gasket by bolts through studs welded to the band and engaging threaded holes in the steel bottom, provided means for keeping this cork-gasket joint tight. Any oil leakage which might occur, due to accident or other cause, was amply provided for by placing the test barrel in a shallow oiltight steel receptacle, large enough to hold all the oil used. With this arrangement, requiring only eight barrels of oil, the test electrodes are freer from field distortion due to adjacent materials than would be possible with the use of containers of metal or other conducting or even semiconducting material, unless such containers were made very large. That is, the use of oil in a barrel of insulating material having about the same dielectric constant as oil, makes possible with a small amount of oil, electric gaps immersed in what, in effect, is a column of oil insulation surrounded by the atmosphere of the test room.

Calculations before construction, and tests after construction, show, for all practical purposes, that this device provides a means of having test gaps in oil completely free from field distortion due to surrounding objects.

The Herkolite cylinder serving as the lead-in bushing is closed at the lower end with a fiber and metal bottom designed to hold oil between it and a steel tubing concentric with the insulating cylinder and through which the upper and adjustable electrode extends into the test barrel. This metal part of the bottom is constructed in such a way as to provide for a well-distributed electric field around the 


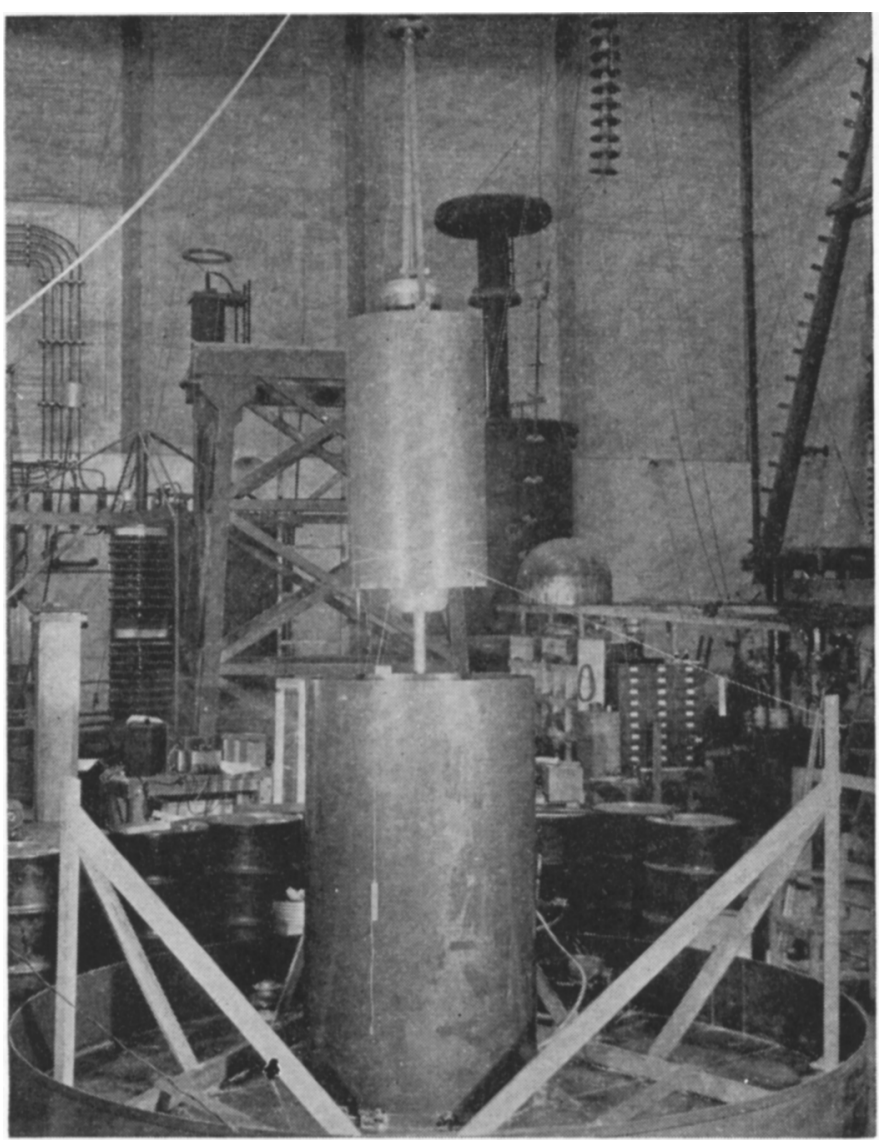

Figure 1. Test barrel and lead-in bushing showing bushing raised for examination and polishing electrodes

lower end of the bushing. The lower electrode, supported by and attached to the bottom of the barrel, was not made adjustable, but constructed so as easily to be changed or removed for cleaning and polishing. During tests the part of the lead-in bushing between outer and inner cylinders is kept filled with oil and flashover from lead-in conductor to the barrel is avoided by having its lower end project into the test barrel a few inches below the surface of the oil in the barrel. This arrangement was proved entirely satisfactory as a means of limiting all arc-overs to the test gap.

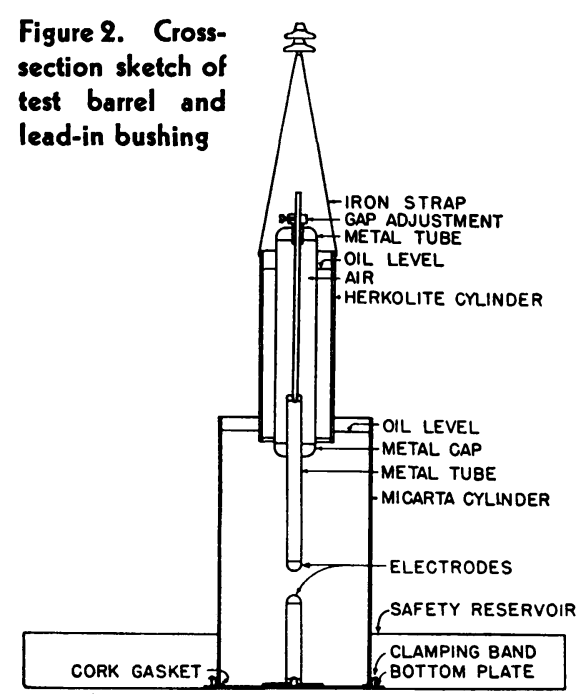

FEBRUARY 1940, Vol. 59
The tests reported in this paper show only the surge voltages required to break down gaps in oil formed between spherically ended cylindrical electrodes of different diameter. All oil used was carefully selected, filtered, and tested according to standard oil testing practice before starting the tests and as often during any test as was necessary to keep the dielectric strength at top value, this top value being determined by a standard oil gap test set capable of applying 30 $\mathrm{kv}$ to the one-tenth inch test gap formed between one-inch-diameter flat electrodes. The oil was considered in proper condition when it would not break down for a two-minute application of this voltage. To keep the oil up to this standard during a test program was not easy, filtering often being found necessary after only a few oil punctures had been made; and frequently after the puncture value of the oil had been decreased, it was necessary to put the oil through the filter several times to restore its dielectric strength to $30 \mathrm{kv}$. Whenever the dielectric strength of the oil dropped to a value of $22 \mathrm{kv}$ or less, the surge voltage required to break down any given gap was reduced an amount which indicates that perhaps as further tests of this type are made, the dielectric strength of the oil during a test run should be determined after practically every oil breakdown. Also, if we wish to know the reason for some of the variable results obtained, it may be necessary to determine oil puncture strength with a precision which will show small variations in dielectric strength in the range above 30 $\mathrm{kv}$, as determined with the standard test cup.

Early in our test program we found that, for consistent breakdown values, only a few discharges could be made between electrode polishings. This was more noticeable for the smaller electrodes than for the larger ones. On rare occasions only one or two discharges which, perchance, occurred from the same spot on one of the electrodes, would make necessary a repolishing of electrodes before consistent breakdown values could be obtained. In all tests it was necessary to observe a time interval of not less than 5 minutes between successive discharges, and for the longer gaps time intervals of 15 to 20 minutes were required for the oil to return to what might be called a normal state.

These influence factors, plus the allprevailing time-lag influence upon surgebreakdown values of voltage for gaps in oil, added to those well-known difficulties encountered in obtaining similar data at power frequencies, soon made evident the fact that breakdown values for gaps in oil would have to be considered as statistical values obtained from a large number of tests, some of which would show values of breakdown voltage varying a considerable amount from any curve drawn to show the probable reasonable breakdown values. In fact, surge-voltagebreakdown values in oil seem to be even

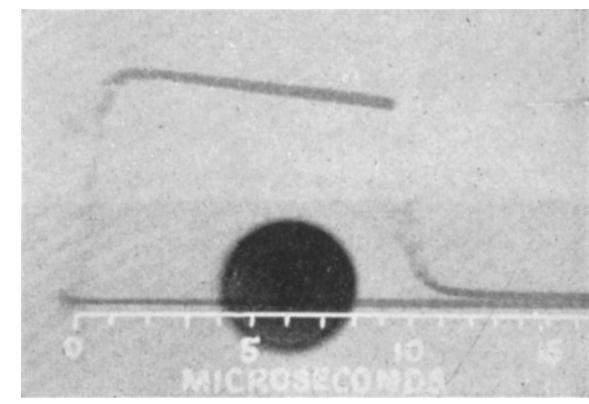

Figure 3. Typical oscillogram, showing oil puncture occurring at $860 \mathrm{kv}$ crest and $91 / 2$ microseconds time lag for eight-inch gap, onehalf-inch-diameter electrodes

more sensitive to the influences which make testing such gaps at power frequency a major operation, than is the case for the power-frequency tests; and it may almost be said that on some days sport breakdown values occurred, for which there just seems to be no way of accounting. 


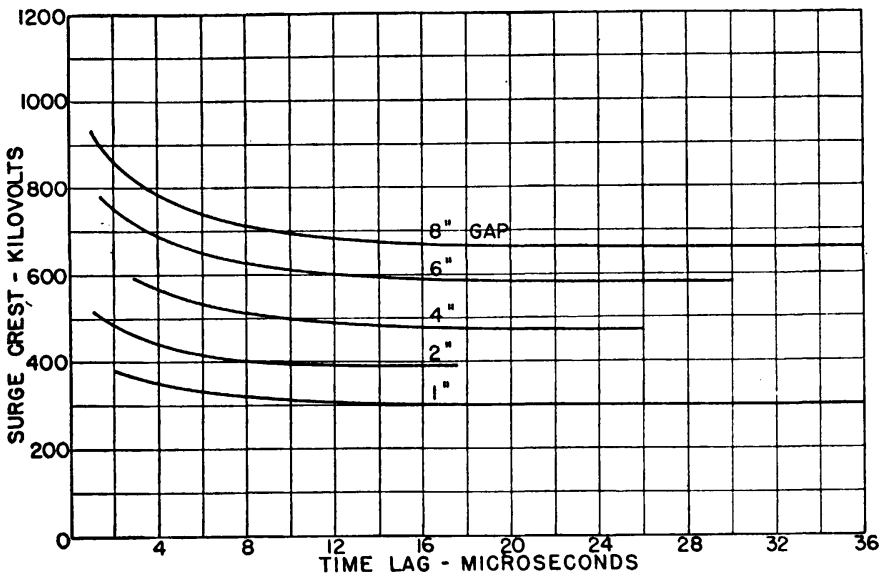

Figure 4. Time-lag curves for one-fourth-inch electrodes with hemispherical ends, $11 / 2 \times 40$ microsecond wave

In making the volt-time tests, the surge generator was adjusted to give a $11 / 2 \times 40$-microsecond negative wave having a crest value well below the minimum flashover voltage required to strike across the gap under test, and for this setting a surge was applied to the gap. The voltage was then increased by small steps until a voltage was reached which would puncture the oil in the gap. When breakdown occurred, the surge voltage which first caused breakdown was applied a number of times. If breakdown occurred for every surge application, the voltage setting on the generator was reduced until breakdown stopped, after which the voltage was again raised until it reached the minimum value which would give breakdown for a majority of the applications.

As a check on this breakdown value, the surge-generator voltage would be al-

Figure 6. Time-lag curves for one-inch electrodes with hemispherical ends, $11 / 2 \times 40$ microsecond wave down.

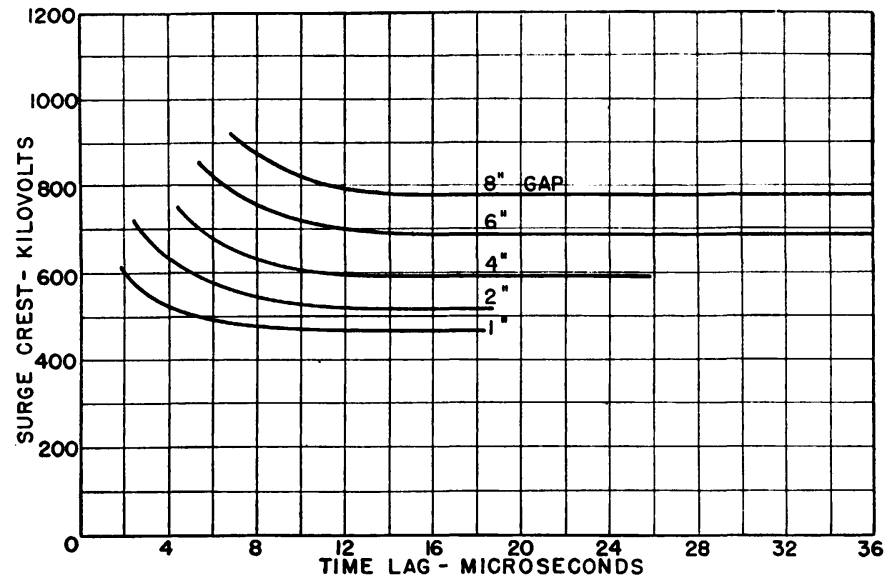

ternately raised and lowered above and below the probable breakdown values. Often a one-step charfge on the surge generator (about three per cent) in the crest voltage value either way would change breakdown performance so that with a three per cent lowering of the crest voltage there would be no breakdowns at all; whereas with a three per cent increase in crest voltage practically every surge application would cause a break-

Having in this way established the probable minimum breakdown voltage for a given gap setting and electrode size, the balance of the volt-time curve was obtained by applying the $11 / 2 \times 40$-microsecond wave at increasing voltages and taking cathode-ray oscillograms of the voltage across the oil gap under test. For each surge-voltage application an oscillogram was made to show the value of the wave from the time of tripping the circuit to breakdown. Figure 3 is a typical oscillogram. In most cases breakdown occurred on the tail of the wave. The crest values of the waves thus recorded were plotted as ordinates on the curve sheets shown in figures $4,5,6$, and 7 , with the time to breakdown shown as corresponding abscissas. The curves thus obtained show minimum breakdown voltages and breakdown voltage versus

Figure 5. Time-lag curves for one-half-inch electrodes with hemispherical ends, $11 / 2 \times 40$ microsecond wave

time to breakdown for higher voltage values. Figure 7 shows the same curve for two-inch spacing, as shown on figure 6 , but shows also the exact location of the points used in plotting the curve.

The probable breakdown curves shown in the paper are considered correct as to values given for prevailing conditions within a value of plus or minus three per cent. Occasionally, however, voltages more than ten per cent above the probable breakdown values shown in the curves would be required to cause breakdown. We think such discrepancies were due to undetermined variable conditions of oil and electrode surfaces, but up to the present time our analysis does not permit a statement as to what these conditions were.

When one of these extremely high firstbreakdown voltage conditions was encountered, the test procedure outlined

Figure 7. Time-lag curves for one-inch electrodes with hemispherical ends, showing spread of actual plotted values from which curve was obtained, $11 / 2 \times 40$-microsecond wave operating procedure was as follows: The
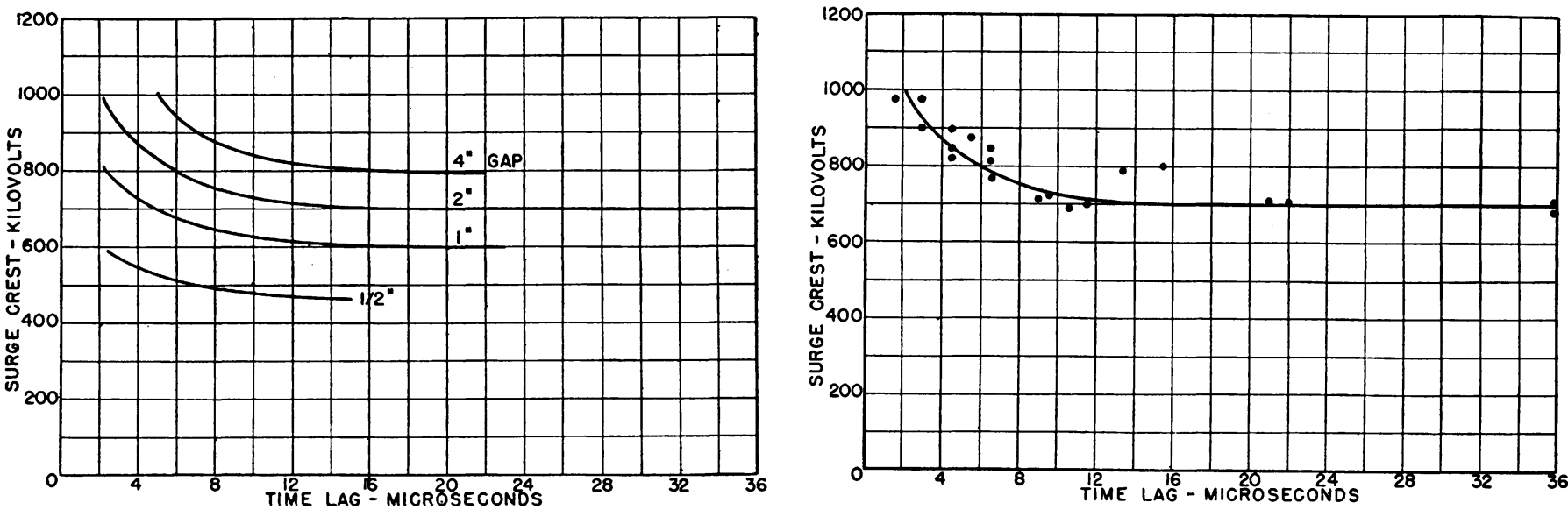


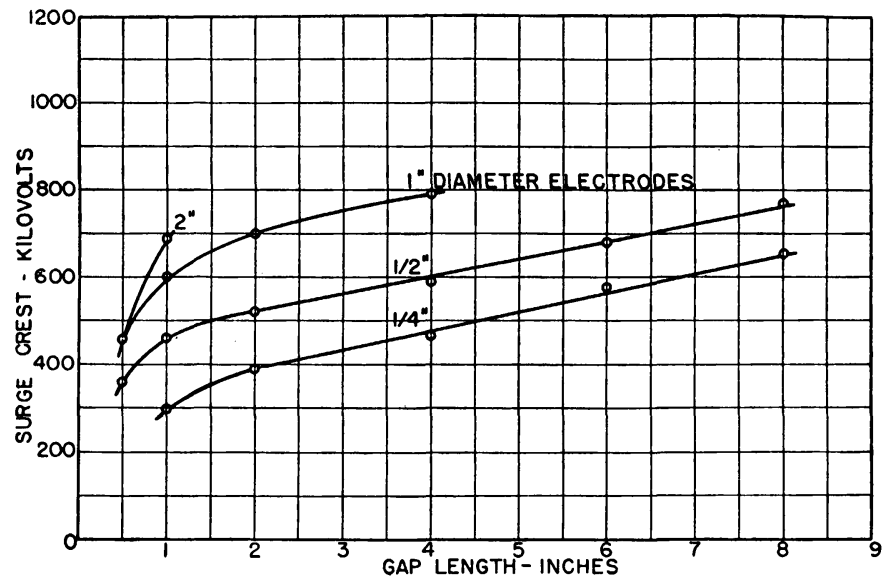

Figure 8. Curve showing relation of gap length to minimum surge crest voltage required for breakdown between cylindrical electrodes with hemispherical ends immersed in oil, $11 / 2 \times 40-m$ icrosecond wave

was reversed and, subsequent to the first breakdown, surges of lower crest voltage than the one causing this first breakdown, but higher than the recognized minimum breakdown, were applied. The voltages for the successive tests were gradually reduced until the probable minimum breakdown voltage for any given gap was reached. The minimum values of voltages found in this manner were in agreement with those found for the same gaps by the more commonly used increasing-voltage procedure. For the one-fourth-inch rods no excessvoltage first breakdowns were in evidence. For the one-half-inch rods this effect was indicated only, and then was limited to the longer gaps. The one-inch rods showed a very pronounced tendency to be subject to this phenomena at small spacings and for the longer gaps high breakdown points definitely occurred. The two-inch rods showed occasional high breakdown voltages for short gaps. If continued tests show any appreciable increase in the percentage of high-breakdown-voltage values, it may be necessary for the larger electrodes to indicate arcover voltage by a broad curve showing the spread, rather than by a single-line probable-breakdown curve.

To show more explicitly what this phenomenon of high breakdown signifies, the following specific instances of such occurrence are noted.

July 11, 1938, five successive surges, all with crest voltage values more than 10 per cent above the probable minimum breakdown value applied to the one-inch gap between one-inch electrodes, failed to puncture the oil. The sixth, or puncturing surge, had a crest value 24 per cent above what appears to be the probable minimum puncture value for the gap.

July 13,1938 , with the same electrodes and same setting, five surges with crest voltages more than 10 per cent above the probable minimum breakdown voltage failed to puncture the oil. Puncture finally occurred at a crest voltage 17 per cent higher than the probable minimum.

July 14,1938 , seven surges which failed to puncture the oil had crest values more than 10 per cent above the probable minimum value applied to one-inch electrodes spaced for a two-inch gap. The breakdown finally occurred at a crest voltage 21 per cent higher than the probable minimum value for this arrangement.

Figure 8 shows data rearranged to enable one to obtain readily the relation between gap lengths and minimum puncture voltages for the gaps included in this report.

It is well to note that the limited amount of data available for design calculations as gleaned from the 1,500 surge tests made to obtain the data presented in this report point strongly to the need of continuing this work in a broader test program extended to a number of our high-voltage laboratories. A search for data pertaining to similar tests for a-c 60 -cycle voltage which might be used in making comparison between 60 -cycle and surge dielectric strengths of oil gaps ${ }^{2}$ disclosed the fact that published 60-cycle data in agreement as to values for gaps formed between different types of electrodes in oil are by no means adequate for our present requirements. Although the ratio of surge crest $1 \frac{1}{2} \times 40$-microsecond wave voltages to 60 -cycle crest voltages required to puncture oil when such voltages are applied to immersed sphere gaps varies with the size of spheres and gap spacing, the present available data indicate that no great trouble will be encountered in designing apparatus if this ratio of crest surge voltage to powerfrequency root-mean-square voltage is taken as three to one until sufficient data for better conclusions are available. Tests made by F. W. Peek ${ }^{3}$ when he introduced the idea of time lag show this ratio of three to one for surges of unknown wave form as compared to 60-cycle breakdown voltages in oil.

To obtain these further data, we invite co-operation from others interested in high-voltage phenomena and recommend the use of test barrels and lead-in bushings made of insulation material having about the same dielectric constant as the insulating liquids to be tested and built according to the general plan of the apparatus described in this paper.

\section{References}

1. A Low-Voltage High-Speed Cathode-Ray Oscillograph, R. Howard Griest. Thesis for doctor of philosophy degree, California Institute of Technology, 1937.

2. Otr Breakdown at Large Spacings, Douglas F. Miner. AIEE Transactrons, 1927, page 248 . 3. Dielectric Phenomena in High-Voltage Enginerring (a book), Peek. McGraw-Hill Book Company, 1929, page 227 .

\section{Discussion}

D. C. Prince (General Electric Company, Philadelphia, $\mathrm{Pa}$.): This paper adds valuable information to our store of knowledge on the behavior of insulating oils. One point of particular value to circuit-breaker designers is brought out very clearly. Under all the conditions investigated the oil presents an impulse ratio of from 2 to 3 . Ordinary air clearances, rod gaps, bushings, and the like, associated with circuit break ers, have impulse ratios of the order of 1.2 . It follows that failure of the oil under impulse is not limiting, a fact of obvious value to designers.

V. M. Montsinger (General Electric Company, Pittsfield, Mass.): Professor Sorensen has given us some very interesting impulse data on the breakdown of oil. Apparently, by exercising great care, he has been able to eliminate the wide variations in oil-breakdown values that usually occur in ordinary methods of testing.

There are, however, two or three points I wish to comment on. +

The author apparently used hemispherical-shaped electrodes to simulate conditions in circuit breakers. The variation of the breakdown voltage with spacing does not seem to follow any law that I have ever observed. For example, his figure 8 shows that for the one-fourth-inch and one-halfinch-diameter electrodes the breakdown voltage varies roughly as the spacing raised to the 0.37 power. For one-inch-diameter electrodes the exponential value of the spacing is even less than 0.37 and bends over, indicating that considerably greater spacings than four inches would give very little increase in breakdown values.

Generally when spheres are used with spacings several times their diameter they act like sharp-cornered electrodes, so far as breakdown versus spacing is concerned. This is especially true when air is the insulating medium.

We have a large amount of data on breakdown of oil for square-edged and round 

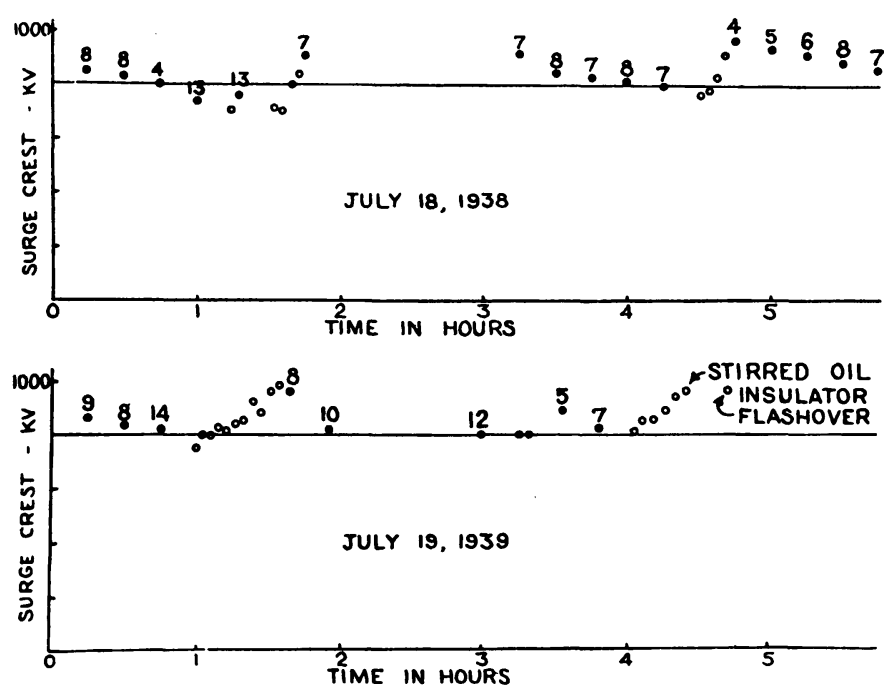

rods (both parallel and at right angles) and in all cases the breakdown is roughly proportional to the spacing raised to the twothird power. It appears from Professor Sorensen's data that for limited spacingsup to six or eight inches-and with small diameter electrodes, the breakdown voltage increases quite slowly with spacing. It would be interesting to know if circuitbreaker engineers find that this is true for the kind of electrodes used in circuit breakers, or do they find that the breakdown strength varies roughly as the spacing raised to the two-third power.

Eric A. Walker (Tufts College, Medford, Mass.): The paper by Professor Sorensen on the "Surge-Voltage Breakdown Characteristics for Electrical Gaps in Oil" is of considerable interest to me because it is very similar in nature to a study which has been started at Tufts College.

In making surge breakdown tests I have felt that one of the most important factors in determining the breakdown strength of the oil is the amount of moisture the oil contains; a factor which is not mentioned by

Figure 2. Time-lag curves for one-inch electrodes with hemispherical ends, $11 / 2 \times 40$. microsecond negative impulse wave was high.
Figure 1 about the same as oil. It is true there will be little field distortion at the oil-Herkolite boundary, but very close to it is the Herkolite-air boundary, where there is a change of dielectric constant and a distortion of field.

A. E. Harrison (California Institute of Technology, Pasadena): A diagram showing the time of application of surges to the one-inch electrodes at four-inch spacing has been prepared to illustrate the phenomenon of application of crest voltages above the probable minimum value without breakdown. Figure 1 of this discussion shows two runs made July 18 and July 19, 1938. The ordinates of the points represent crest voltages, while the time in hours gives the intervals of time between application of surges. The figures above certain points give the breakdown time in microseconds. No breakdown occurred for surges indicated by open circles.

I interpret these data as follows: AppliProfessor Sorensen, except to say that the oil was periodically filtered.

Oil in contact with air undoubtedly contains water in two forms: water in solution and water suspended as small droplets which gradually settle out and collect as free moisture at the bottom of the tank. The balance between the two types is controlled by the temperature. As the oil cools less water is held in solution, and more in suspension. I do not believe that moisture in one form will have the same effect as moisture in the other, so I feel that before consistent results can be obtained the total amount of moisture the oil contains and the temperature must be controlled and recorded.

If oil contains moisture in suspension it appears difficult to reproduce results because each successive shot draws more moisture into the gap. The reason is self-evident. Water has a higher dielectric constant than oil and so is impelled into the region where the electrical stress is greatest.

In our tests a number of sludged samples of oil were found, which had relatively high breakdown strengths when tested on a short chopped wave; and relatively low strengths when tested at 60 cycles in the standard gap. The power factor of these sludged samples

I wonder if Professor Sorensen does not emphasize too much the advantages of constructing a tank of Herkolite or some other cation of surge voltage less than that required for breakdown changes the condition of the electrode surface, and/or the condition of the oil so that the gap will not break down when the probable minimum value of crest voltage is exceeded. The influence of operating procedure has not been established, although recent evidence points to the conclusion that the stirring of the oil after breakdown has occurred may account for this behavior. Stirring the oil when breakdown had not occurred, and waiting 15 minutes (the next to last point on trated) would not cause breakdown to occur, however. Once breakdown has occurred at a high voltage, breakdown will then occur at the probable minimum voltage. (Note point at time two hours on July 19.)

This unusual behavior was quite consistent on days when it occurred, but there were times when the phenomenon failed to occur for no apparent reason. Also, this phenomenon did not seem to occur when the oil around the gap was not stirred after a breakdown, although failure to stir the oil seemed to reduce the strength of the oil in

Figure 3. Time-lag curves for two-inch electrodes with hemispherical ends, $11 / 2 \times 40$. microsecond negative impulse wave July 19 and other similar tests not illus-
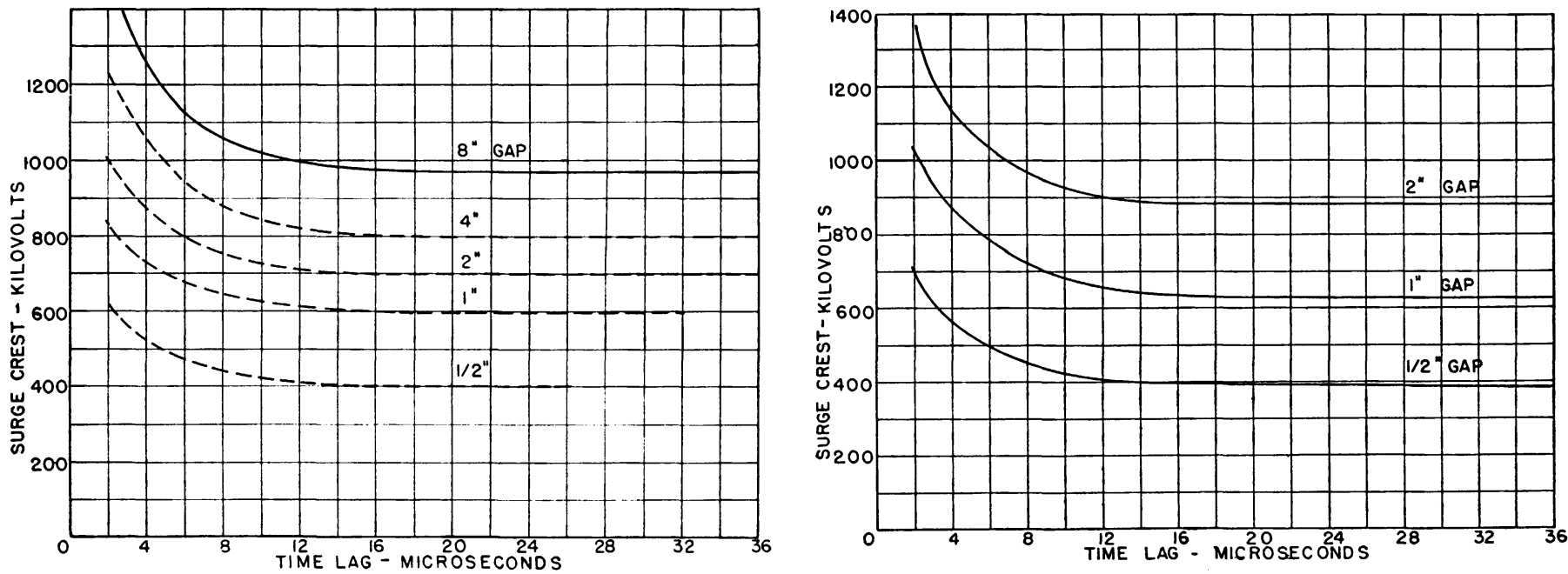


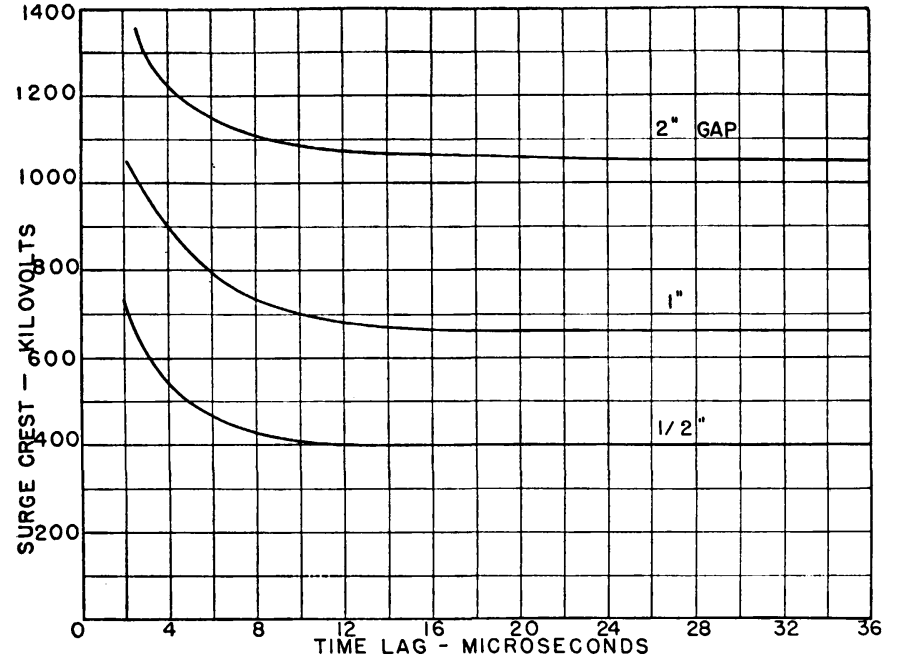

Figure 4. Time-lag curves for four-inch electrodes with hemispherical ends, $11 / 2 \times 40$ microsecond negative impulse wave

some cases. We would be interested in hearing possible explanations of this unusual behavior.

A. Lovoff (California Institute of Technology, Pasadena): I would like to present additional data on the breakdown characteristics of oil, obtained in the high-voltage laboratory of the California Institute of Technology subsequent to the writing of Doctor Sorensen's paper.

Figures 2, 3, and 5 of this discussion show an extension of the data for the one- and two-inch electrodes and figures 4 and 5 show data for the four-inch electrode not included in the paper. The dotted curves are the same as those presented by Doctor Sorensen in his paper and are reproduced in this discussion for the sake of completeness. The curves of figure 5 and a curve for point electrodes if all plotted on one log-log plot will show for the larger gap spacings the manner in which the curves for the variousdiameter electrodes approach the needlegap curve. Such a log-log plot will be included in a paper now in preparation, hence will not be given in this discussion.

Recent preliminary power-frequency-voltage breakdown tests on these electrodes to determine the one-minute hold voltage disclose that the ratio of minimum surge breakdown voltage to the one-minute-hold power-frequency voltage (crest) is approximately 2.2. This impulse ratio of 2.2 checks with the figure given by Doctor Sorensen.

The anomaly of the application of greater than the established minimum breakdown surge voltages without oil breakdown occurring, as discussed by A. E. Harrison, may po:sibly be explained as follows. After the oil has been broken down in the gap and the oil stirred, a high enough concentration of carbon particles might remain in the vicinity of the gap to distort the field in such a way as to increase the breakdown voltage. I have noticed this failure-to-breakdown phenomena at higher than the established minimum surge voltage when testing the one-inch electrodes at the four- and eightinch spacings. In that case the oil after being subject to several successive shots at

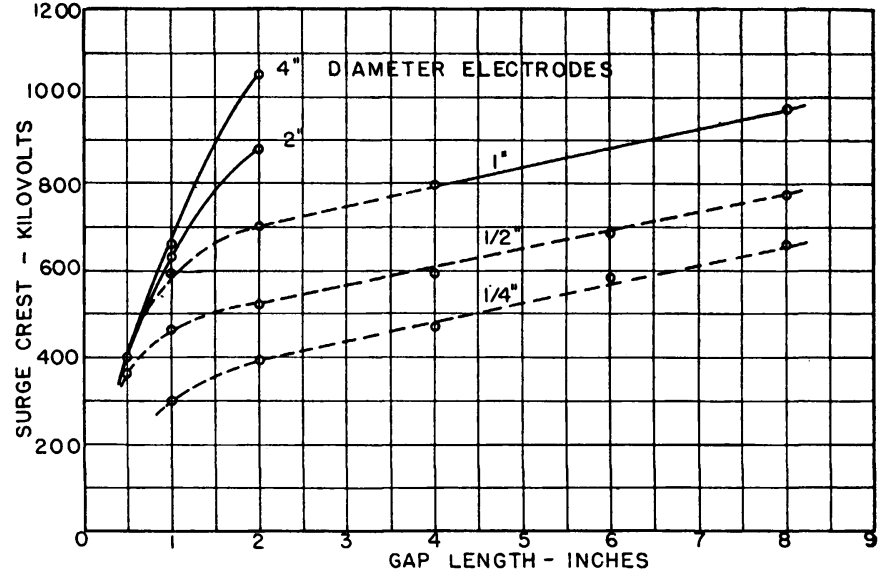

Figure 5. Curves showing relation of gap length to minimum surge crest voltage required for breakdown between cylindrical electrodes one-fourth-inch, one-half-inch, one-inch, twoinch, and four-inch diameter, with hemispherical ends, the gaps being immersed in transformer oil and subjected to $11 / 2 \times 40$-microsecond negative impulse waves down status by proceeding as follows: the oil was very thoroughly stirred and after a ten-minute wait subjected to a surge voltage just above the probable minimum, when it was found to resume a normal performance. Three such instances noted in my records tend to substantiate the contention that foreign matter introduced during breakdown is the cause of this no-breakdown phenomena at voltage values higher than the probable minimum surge breakdown voltage.

Royal W. Sorensen: Mr. Montsinger's comments are valuable additions to the bit of information regarding surge-voltage performance for electrical conductors in oil included in this paper, which we hope has initiated a program of testing that will give us a more extensive knowledge of surge voltage performance.

All of the statements in our papers do not seem to convey to $\mathrm{Mr}$. Montsinger the same meaning as that which we intended. Our reason for using rods with hemispherical ends as electrodes was not to simulate the conductors in circuit breakers, because circuit breakers do not use electrodes of that shape. The electrode shape we used was chosen because the sphere gap is a standard method of making voltage measurements. Spheres in oil with supporting shanks of small diameter, however, are more susceptible to shank influences than are similar spheres in air. Hence to avoid possible variations in arc-over voltage due to differences in shank sizes which might be used. rod electrodes with the ends rounded off as hemispheres were used.

Subsequent to the writing of the paper under discussion, we have made tests which have given us much data not available for the paper. Some of these additional data are recorded in the curves of figure 5 of $\mathrm{Mr}$. Lovoff's discussion. It is interesting to note that the extended curves including these additional data are satisfactorily in accord with the curves of the paper's figure 8 , to which Mr. Montsinger has referred. It is true that for the larger spacings, as $\mathrm{Mr}$. Montsinger has pointed out, not only the one-inch-diameter electrode, but also the other electrodes show smaller increases in voltage breakdown values as the spacings are increased. When, however, we can obtain a high enough voltage to get out on the straight-line parts of the curves, as has been done for the one-fourth-, one-half-, and oneinch electrodes, it is interesting to note that the curves are approximately parallel when plotted on rectangular co-ordinate paper, as is the case for figure 8 of the paper under discussion, and figure 4 of $\mathrm{Mr}$. Lovoff's discussion.

Mr. Montsinger states that "generally when spheres are used with spacings several times their diameter, they act like sharpcornered electrodes so far as breakdown versus spacing is concerned." Some of our data, not yet published, bear this out, because for all electrodes when the spacing is sufficiently increased, we find that the curves of breakdown voltage versus gap length for the electrodes approach the point-gap curve.

$\mathrm{Mr}$. Montsinger calls attention to the fact that he has available "a large amount of data on breakdown of oil for square-edged and round rods (both parallel and at right angles) and (that) in all cases the breakdown is roughly proportional to the spacing raised to the two-third power." I presume he refers specifically to surge-voltage breakdown. I would be interested in seeing these data, not only to note what the surge breakdown values are, but also to note whether parallel and crossed rods for surge voltages have (as is the case with powerfrequency voltages) the same breakdown values for parallel and crossed rods, a fact long ago noted in Schwaiger's "Theory of Dielectrics."

Mr. Montsinger also states that for limited spacings up to six or eight inches the voltage increases slowly with spacing. Also an inspection of the curves shows that with such spacings tests on electrodes having diameters of one inch or less give for these spacings curves that are approximately straight lines. I cannot, however, give any information as to what circuit-breaker engineers find for the kind of electrodes used in circuit breakers because I have not seen any published data for such tests. The reason for the small amount of such data available 
is perhaps found in D. C. Prince's discussion of our paper, wherein he says "under all the conditions investigated (and reported in the paper) the oil presents an impulse ratio of from 2 to 3 , whereas the parts of the breaker which are in air have impulse ratios of the order of 1.2." In other words, what we have done is verify the fact that oil under impulse is not a limiting factor in design because oil strength under normal and recovery voltage has taken care of the impulse factor.

E. A. Walker's discussion calls attention to the importance of giving careful attention in making these studies to the amount of moisture in the oil under test and the form in which the moisture is present. Very early in our experiments, as was stated in the paper, we found that breakdown values were very sensitive to the oil moisture content. So far we have simply avoided most of the difficulties of variability due to this moisture content by using only oil of high dielectric test; for example, oil which would stand 30,000 to 40,000 volts when tested with a standard 0.1 -inch oil testing gap. In fact, as Mr. Walker suggests, there is no doubt a fertile field for investigation to determine the exact quantitative influence of water content and also of temperature on surge-voltage-breakdown values for oil.

I do not think, as $\mathrm{Mr}$. Walker has stated, that we have at all overemphasized the advantages of using a test tank of material which has a dielectric constant approximately the same as that of oil, because after all the prime reason for the use of a tank made of insulation material rather than metal is the avoidance of the difficult lead-in bushing problem and the use of the large amount of oil required when steel tanks are used. The fact that the dielectric constant of the insulation material used is so nearly the same value as the constant for transformer oil and that the dielectric constants for both the oil and the insulation material is only two to three times the constant for air, is a happy coincidence which makes our plan practical; whereas it would not be so good if we had to use a barrel made of some material such as porcelain, which has a much higher dielectric constant than the material of which our test barrel is made.

At present $I$ have no explanation for the phenomena described in Mr. Harrison's discussion and can only confine my remarks to expressing appreciation of the large amount of careful, conscientious work which he has done in obtaining for me much of the data used in this paper.

Mr. Lovoff also has added to the paper data which he has obtained and which extend the curves used in the paper to values beyond those available at the time the paper was written. To him and to other students who have helped in this work, I am deeply indebted, for without their help the large amount of testing necessary to produce this report could not have been obtained. In fact, like most research work of today, the results presented in this paper are available only because of much co-operation by many persons and it would certainly be unfair to close our discussion without expressing appreciation to the Kelman Electric and Manufacturing Company, which provided much of the equipment used in making the tests, and to Messrs. Kelman, Sadler, and Thompson, who contributed valuable suggestions.

\section{Sensitive Ground Protection for Radial Distribution Feeders}

\author{
LLOYD F. HUNT \\ FELLOW AIEE
}

HERE are three reasons for isolating or de-energizing grounded feeders: first, danger to life; second, danger to property; and third, to permit joint use of pole lines with the telephone companies. The first two are very difficult to evaluate, but in certain territories a means of isolation is very important. The third reason can be given a definite value, and the economies resulting from joint use of pole lines can more than justify this proposed scheme of sensitive ground protection for radial feeders.

This paper will not discuss the merits of leaving a ground-faulted feeder in service for the continuity of service, as may be the practice by some utilities, but discusses the methods of clearing ground faults that may normally occur on radiäl feeders.

\section{Ground Faults}

The magnitude of ground currents on lower-voltage feeders with solidly grounded neutral transformers varies more according to the contact resistance of the fault than it does for the location of the fault. This effect is greater, the lower the voltage of the circuit. ${ }^{1}$ The usual voltages used for radial feeders range from $2.3 \mathrm{kv}$ to $22 \mathrm{kv}$.

Many ground tests have been made on $2.3-, 4-, 7-, 11-$, and $16.5-\mathrm{kv}$ systems of the Southern California Edison Company, Ltd. These tests all have shown conclusively that the contact resistance has a controlling influence on the magnitude of ground current.

Tests on a 4-kv solidly grounded neutral circuit show very small amounts of current when bare wire is groundfaulted as follows: In dust 0.3 to 0.6 amperes, in grass 1 to 3 amperes, in muddy water 25 to 30 amperes. Other tests on $4 \mathrm{kv}$ on dry pavement and dry

Paper 39-131, recommended by the AIEE committee on protective devices, and presented at the AIEE combined summer and Pacific Coast convention, San Francisco, Calif., June 26-30, 1939 Manuscript submitted April 14, 1939; made available for preprinting May 26, 1939.

Lloyd F. HUNT is protection engineer and $J$. $H$. VIvian is technical assistant and superintendent of relays, Southern California Edison Company, Ltd., Los Angeles.

1. For numbered reference, see end of paper.

\author{
J. H. VIVIAN \\ ASSOCIATE AIEE
}

sand soil, where there had been no rain for several months, show that practically no current flows. A series of tests were made on a $7-\mathrm{kv}$ impedance-grounded neutral system by dropping a $2 / 0$ bare conductor on a green lawn. In this case, with about 20 feet in contact, the current was in the order of 2 to 3 amperes during the few minutes of each test. In another test, with a ground connected to a fivegallon can in mud, 35 amperes flowed in an $11-\mathrm{kv}$ solidly grounded neutral circuit. Tests were made on $16.5-\mathrm{kv}$ solidly grounded neutral circuit by dropping a partial span in a dry stubble field. It was necessary for the conductor to touch a green weed or come in contact with a conducting portion of earth before current would flow. Some of the times the conductor would lie in this stubble field as if dead; then all of a sudden a breakdown to earth would occur which was sufficient to cause current to flow. From this particular group of tests it seemed as though at certain times, when the conductor was dropped, it would break down,

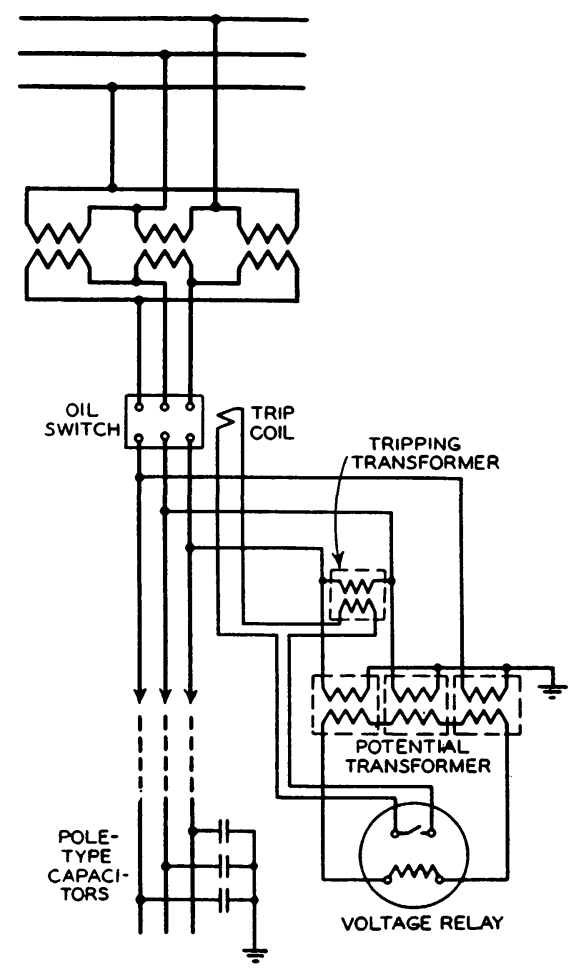

Figure 1. Sensitive ground protection for single-circuit delta system 